\title{
Comparing Scapular Position and Scapular Dys- kinesis in Individuals with and without Rounded Shoulder Posture
}

\author{
Elham Sarabadani Tafreshi' ${ }^{1}$, Afsun Nodehi Moghadam ${ }^{1 *}$, Enayatolah Bakhshi' $^{2}$, Mahan Rastgar
}

1. Department of Physiotherapy, University of Social Welfare and Rehabilitation Sciences, Tehran, Iran.

2. Department of Biostatics, University of Social Welfare and Rehabilitation Sciences, Tehran, Iran.

Citation: Sarabadani Tafreshi ?, Nodehi Moghadam A, Bakhshi ?, Rastgar ?. Comparing Scapular Position and Scapular Dyskinesis in Individuals with and without Rounded Shoulder Posture. Physical Treatments. 2015; 5(3):127-136.

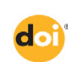

Article info:

Received: 21 Apr. 2015

Accepted: 30 Aug. 2015
Keywords:

Rounded shoulder posture, Static scapular position, Scapular dyskinesis

\begin{abstract}
A B S T RA C T
Purpose: Altered kinematics of the scapula or scapular dyskinesis (downward rotation, anterior tilt, and protraction) contribute to impingement syndrome by decreasing the subacromial space. Given the critical role of scapular position and movement in the function of the shoulder, the aim of this study was to compare scapular position and dyskinesis in individuals with and without rounded shoulder posture.

Methods: By employing the convenience sampling method, 21 individuals with rounded shoulder posture (11 females and 10 males; average age: 22.95 years) and 23 individuals without rounded shoulder posture (13 females and 10 males; average age: 22.43 years) were enrolled in this study through a case-control design. The scapular dyskinesis test was used to observe alterations in scapulohumeral rhythm in the sagittal and frontal planes of the arm. Also, the scapular position was examined according to the Kibler test. Data were analyzed using SPSS 21. We used the Independent t-test and Mann-Whitney test to compare the differences between the two groups.
\end{abstract}

Results: There were no differences in scapular dyskinesis between the two groups $(\mathrm{P}>0.05)$. The prevalence of subtle or obvious scapular dyskinesis in individuals with rounded shoulder posture was greater than those without rounded shoulder posture, but the difference was not statistically significant. Furthermore, no significant difference was found in static scapular position (Kibler test) of the dominant and non-dominant sides between the two groups $(\mathrm{P}>0.05)$.

Conclusion: There were no significant differences in scapular position and scapular movement pattern between the individuals with and without rounded shoulder posture.

\section{Introduction}

capula has an important role in the creation of uniform and harmonious movement of the shoulder-girdle [1]. Thus, alterations in the normal position of the scapula and the functions of its stabilizing muscles can be an important factor in the development of abnormal biomechanics of the shoulder girdle [2].

\section{* Corresponding Author:}

Afsun Nodehi Moghadam, PhD

Address: Department of Physiotherapy, University of Social Walfare and Rhabilitation Sciences, Koodakyar Ave., Daneshjoo Blvd., Evin, Tehran, Iran. Phone: +98 (21) 22180039

E-mail: afsoonnodehi@gmail.com 
The scapular position in relation to the thorax is important because its abnormal position disrupts the normal bio-mechanics of the shoulder joint, leading to injury or abnormal posture [3].

The rounded shoulder posture (RSP) (forward shoulder, round shoulder) is one of the common postural abnormalities [4] that accounts for $60 \%$ of shoulder abnormalities $[5,6]$. Its incidence has been reported as $73 \%$ in the right side and $66 \%$ in the left side [7]. RSP has been defined as an increase in the distance between the inferior angle of the scapula and the spinous process of the vertebrae $[6,8]$. It is different from kyphosis, as kyphosis occurs in the sagittal plane while RSP occurs in the horizontal plane [9]. RSP with protraction, downward rotation, and anterior taping of the scapula's position is accompanied by the increase in cervical lordosis and kyphosis of the upper thoracic part.

Several factors may be associated with this postural disorder. One of these factors is shortness of the small pectoral muscle [10-14]. It is believed that the RSP brings the small pectoral muscle terminal heads (ribs 3, 4 , and 5) close to its beginning (coracoid process), resulting in the shortness of the pectoral muscle[15]. This abnormality can be due to the more forward traction of the shoulder than the usual anatomical mode, resulting from excessive exertion in sports, shortness, and stiffness of the anterior shoulder girdle muscles such as the serratus anterior muscles, small chest muscles, and superior trapezius muscles. This may also be caused due to the weakness and lengthening of the intermediate and the inferior trapezius muscles $[6,9,16]$. Muscle length changes developed in RSP may lead to disruption in the scapulohumeral normal rhythm, impingement of the rotator cuff tendons, damage to acromioclavicular joint, bicipital tendonitis, and the creation of painful trigger points in the area [9].

Scapular muscle weakness or dysfunction, muscle fatigue, and changes in the cervical spine or thoracic posture alter the scapular kinematics, resulting inwinging or scapular asymmetry in the static position or within the movement range of the upper limb. This condition is called scapular dyskinesis [17]. The physiological impacts of a rounded shoulder in terms of prevalence and frequency vary from one person to another.

As the distance between the shoulder bones increases, the resilience of shoulder-girdle muscles decreases [6]. Due to constant contraction of pectoral muscles, rounded shoulders can limit thoracic expansion and thus lead to labored breathing [18]. Stiff pectoral muscles may also pull shoulder-girdle forward out of its anatomic movement plane and cause decreased range of motion, discomfort, or even pain. Constant contraction for a long period will shorten the stiff muscle, lengthen or weaken the counter muscle group in the posterior, and cause muscle injury [6]. Internal rotating shoulders lead to scapular protraction, which reduces the space of the posterior canal and puts pressure on the vascular-neural network [6]. It may further result in reduced subacromial space, and the patient becomes prone to the shoulder impingement syndrome $[6,19]$.

Therefore, examining the scapular movement during shoulder examination is important. However, the clinical examination of this joint is difficult due to the presence of a large volume of soft tissues that cover this joint and the complex 3D movement of this joint during the upper limb elevation movement.Many researchers have investigated the methods that examine the scapula movement $[20,21]$. Some of these methods have examined the scapula in the static position, such as the Kibler method, which measures the scapula's lateral slide in threestatic positions of the upper limb [5]. By contrast, there are methods that have studied the scapular movement in a dynamic form. Mcclure developed one such method in 2009 in which scapular dyskinesis is measured in the dynamic mode, i.e., when the upper limb is in motion, the scapula should move in line with the humerus [22]

Many people, including students, find it difficult to maintain the proper and correct sitting posture for long hours during the day (because of fatigue in the lumbar extensor muscles) [23]. Hence, most of them use the comfortable sitting or reclining position [24].Becoming accustomed to the reclining position can cause RSP deviation in those individuals [25]. According to the studies, this postural deviation can impact scapular kinematics [2629]. Nevertheless,no other research had been carried out to specifically examine the circumstances of these changes in individuals with RSP. Therefore, the aim of the present study was to gather more information in this regard, so as to improve the preventive and rehabilitation programs for people with RSP .The study also aimed to examine and compare the probable impacts of RSP on scapula's position and kinematics in healthy individuals and those with RSP.

\section{Materials and Methods}

In this case-control study conducted in the winter of 2015, convenience sampling method was used to select 21 individuals with RSP (11 females and 10 males) from among the students (age range: 18 to 30 years) of Biomechanics Laboratory of the Department of Physiotherapy 
at the University of Social Welfare and Rehabilitation Sciences.Twenty-three participants (13 females and 10 males) without RSP, who were matched with the other group in terms of age, height, and weight, were also selected.The sample volume was calculated by using similar studies and as per the following formula with $80 \%$ confidence level and 5\% error probability for each group [30]. In order to increase the power of the study, the number of individuals under study was increased to 23 in the healthy group and 21 in the patients group.

$$
n=\frac{\left[\left[z_{1-\alpha / 2}+z_{1-\beta}\right] 2 \sigma_{p}\right]}{(d)}=\frac{((2.8) 2 \times 0.27)}{(0.5)}=16.94=17
$$

The study was carried out with the approval of the Ethics Committee of Social Welfare and Rehabilitation Sciences University. The inclusion criterion for healthy people was the normal posture of head and neck and shoulders. The inclusion criteria for the group with RSP was having the position of the acromion process in the anterior of the plumb line $[9,31]$ and having more than $2.6 \mathrm{~cm}$ distance between the external posterior surface of the acromion to the surface under study in the supine position [32]. The exclusion criteria were pain in shoulder or neck area $[10,33]$, a history of instability, dislocation, fracture, or movement limitation in the shoulder area [10], a history of shoulder or neck surgery [10, 33], malignant tumors in the shoulder or cervical area [34], neurological symptoms [10,33], cardiovascular diseases $[10,33]$, hereditary and congenital abnormalities, lefthandedness, and pregnancy. The participants entered the study after receiving full information on the conditions of the study and having filled out the informed consent forms and the questionnaires containing background information.

\section{Method to assess rounded shoulder posture}

The initial assessment was carried out through observation and using the plumb line. The acromion process should be in the anterior of the plumb line that could be considered rounded shoulder [31]. Then, while the participant was in the supine position lying on the bed, with limbs (elbow flexed) placed on the abdomen, the external-posterior surface of the acromion process was found through probing by hand and was marked by ballpoint pen [13]. Afterward, the distance between the externalposterior surface of the acromion process to the surface under examination was measured in centimeters using a ruler and was recorded. If this distance was greater than $2.6 \mathrm{~cm}$, it would be considered as a rounded shoulder. This method has high credibility and intraclass correlation $(\mathrm{ICC}=0.95)$ [32]. For more accurate examination of the shoulder posture, the shoulder angle, i.e., the angle between the vertical line passing through the posterior surface of the spinous process of the seventh cervical vertebra and the acromion was measured for both the dominant and non-dominant sides [35, 36].

In this method, the acromion process and then the seventh cervical vertebra spinous process were identified through probing by hand and were marked by a

highlighting marker. For identifying the seventh cervical vertebra, the participant does cervical flexion and extension. While doing cervical extension, if the sixth vertebra spinous process cannot be found through probing, the seventh vertebra spinous process would remain prominent [37]. The participants stood in a relaxed position and with legs set apart so as to be consistent with the shoulder width, and they are asked to look straight forward, in a totally natural posture [36]. Then, by using Canon IXUS camera set at shoulder height of the participant, the shoulder's side view was photographed, and by using AutoCAD 2012, the degree of this angle was measured [38]. Based on this measurement, a shoulder angle equal to or greater than 52 degrees $(\mathrm{SA} \geq 52)$ was considered as rounded shoulder [35].

\section{Method of measuring the position of the scapula:} Kibler lateral scapular slide test

To measure the position of the scapula in the static position, the Kibler test was used. This test takes place in three positions: in the first position, the arms are hanging alongside the body with thumbs looking forward; in the second position, the hands rest on the iliac crests while the thumbs are positioned behind; and in the third position, the arms are placed in 90 degrees abduction with maximum internal rotation of the shoulder while the elbows are in straight position and thumbs looking down to the floor. In all the three positions, the distance between the seventh and eighth vertebrae to the lowest point of the scapula was measured in order to measure the inferior side displacement (Kibler).However, one of these positions, i.e., the first position, has higher reproducibility [39]. Therefore, in this study, only the first position was examined for comparison. To this end, the distance between the seventh and eighth vertebrae to the lowest point of the scapula (the inferior angle) in the first positionwas measured by using a tape measure [5].

\section{Method to conduct the scapular dyskinesis test}

The participant was asked to stand in the upright position while the hands were alongside the body, elbows 
straight, and shoulders in the neutral position as regards rotation. The examiner stood at a distance behind the participant. The participant carried out each motional test 5 times in the flexion and abduction directions [22]. Then the participant was asked to take a 1.4 to $2.3 \mathrm{~kg}$ weight in each hand. The weights are determined according to the individual's body weight in a way that the $1.4 \mathrm{~kg}$ weight was assigned to the participants weighing less than 68.1 $\mathrm{kg}$ and the $2.3 \mathrm{~kg}$ weight to the participants weighing more than $68.1 \mathrm{~kg}$. Then, with a 3 -second count while the thumbs were positioned upwards, both hands were brought up simultaneously in the sagittal plane up to the extremity of the upper range and then brought down within 3 seconds. The elevation movement in the sagittal plane was repeated 5 times, and during each repetition, the scapular's motional pattern was graded. Next, and in the same order, the elevation movement was repeated in the frontal plane for 5 times, and the scapular movement pattern was graded. The criteria for grading the movement pattern are as follows:

\section{Normal}

During the 30-60 degree movement, the scapular movement is stable or moves slightly. With the elevation of the arm, it rotates uniformly and continuously upwards, and during the arm lowering, it rotates uniformly and continuously downwards. There are no signs of winging.

\section{Scapular dysrhythmia}

Dysrhythmia means that scapular elevation and protraction are more or earlier than its normal pattern. Nonuniform movement can be seen during the arm upwards and downwards motion or a quick rotation seen during the arm descent.

\section{Winging}

The inner edge or the inferior angle of the scapula protrudes from the thoracic posterior. During the elevation (five repetitious movements), one of the following grades is given to the scapula movement:

- Normal/N movement: No sign of abnormality is observed,

- Subtle/S abnormality: There is a subtle or questionable sign of abnormality,

- Obvious abnormality: There is an obvious abnormality in at least 3 cases of the 5 repetitions (significant dysrhythmia or winging) [22, 40].

In this study, SPSS was used for carrying out statistical analyses. For determining the normal distribution of variables, the Kolmogorov-Smirnov statistical test was used. For comparing the two groups, the Independent ttest for quantitative variables and Man-Whitney test for qualitative variables were used. The significant level was considered as $\mathrm{P}<0.05$.

\section{Results}

Demographic information of the study participants are presented in Table 1. As observed, there is no significant difference between the two groups with regard to demographic variables. To examine the reproducibility, a group of 10 people was tested on their right side limbs. ICCwas used to test reproducibility from the relative aspect, and the standard error of measurement (SEM) was

Table 1. Comparing demographic specifications between 2 groups with and without rounded shoulders based on the Independent t-test.

\begin{tabular}{|c|c|c|c|c|c|c|c|c|}
\hline \multirow[b]{2}{*}{ Variable } & \multicolumn{2}{|c|}{ Mean } & \multicolumn{2}{|c|}{ SD } & \multicolumn{2}{|c|}{ Difference } & \multirow[b]{2}{*}{$\mathbf{t}$} & \multirow[b]{2}{*}{$\begin{array}{c}\text { P-value } \\
(P<0.05)\end{array}$} \\
\hline & $\begin{array}{l}\text { Healthy } \\
\text { group, } \\
23 \text { persons }\end{array}$ & $\begin{array}{l}\text { Rounded } \\
\text { shoulder } \\
\text { group, } \\
21 \text { persons }\end{array}$ & $\begin{array}{l}\text { Healthy } \\
\text { group, } \\
23 \text { persons }\end{array}$ & $\begin{array}{c}\text { Rounded } \\
\text { shoulder } \\
\text { group, } 21 \\
\text { persons }\end{array}$ & $\begin{array}{l}\text { Mean } \\
\text { value }\end{array}$ & $\begin{array}{l}\text { Standard } \\
\text { deviation }\end{array}$ & & \\
\hline Age $(y)$ & 22.43 & 22.95 & 2.50 & 2.62 & 0.52 & 0.12 & 0.67 & 0.51 \\
\hline Height $(\mathrm{cm})$ & 171.35 & 173.43 & 11.39 & 8.66 & 2.08 & 2.73 & 0.68 & 0.50 \\
\hline Weight (kg) & 64.39 & 65.67 & 13.38 & 12.82 & 1.28 & -0.56 & 0.32 & 0.75 \\
\hline $\begin{array}{l}\text { BMI (Body Mass } \\
\text { Index) (kg. } \mathrm{m}^{2} \text { ) }\end{array}$ & 12.72 & 21.68 & 2.42 & 2.80 & 0.04 & 0.38 & 0.05 & 0.96 \\
\hline
\end{tabular}


Table 2. Examining the absolute and relative reproducibility indices for variables under study measured on the right side.

\begin{tabular}{ccc}
\hline Variable & ICC & SEM \\
\hline Distance from acromion to flat & 0.97 & 0.42 \\
Shoulder angle & 0.97 & 4.3 \\
First position in the Kibler test & 0.91 & 0.66 \\
Second position in the Kibler test & 0.68 & 1.17 \\
Third position in the Kibler test & 0.60 & 1.29 \\
Scapular dyskinesis in flexion & 0.83 & 0.33 \\
Scapular dyskinesis in abduction & 0.84 & 0.40 \\
\hline
\end{tabular}

Table 3. Comparing the scapular lateral slide in Kibler test first position (distance between the seventh and eighth vertebrae to scapular inferior angle), between 2 groups of with and without rounded shoulder.

\begin{tabular}{|c|c|c|c|c|c|c|}
\hline Variable & Group & No. & Mean & SD & $\mathbf{t}$ & P-value \\
\hline \multirow{3}{*}{ Position of right side scapula $(\mathrm{cm})$} & Healthy & 23 & 9.07 & 1.69 & \multirow{3}{*}{1.26} & \multirow{3}{*}{0.22} \\
\hline & & & & & & \\
\hline & Rounded shoulder & 21 & 9.75 & 1.91 & & \\
\hline \multirow{3}{*}{ Position of left side scapula $(\mathrm{cm})$} & Healthy & 23 & 8.93 & 1.83 & \multirow{3}{*}{0.56} & \multirow{3}{*}{0.55} \\
\hline & & & & & & \\
\hline & Rounded shoulder & 21 & 9.30 & 2.19 & & \\
\hline
\end{tabular}

used with regard to an absolute aspect. The results for variables under study are listed in Table 2. According to the classification by Munro et al ., ICC between $0 \%$ and $25 \%$ is considered as very low reproducibility, $26 \%$ to $49 \%$ as low reproducibility, $50 \%$ to $69 \%$ as medium reproducibility, $70 \%$ to $89 \%$ as high reproducibility, and from $90 \%$ to $100 \%$ as very high reproducibility. In addition, lower SEM indicates more reliability of the difference between data obtained from the two groups [41]. As seen in Table 2, the variables for shoulder angle, the distance of the acromion to flat and the first position in the Kibler test had very high intrasession reproducibility, and scapular dyskinesis had high reproducibility in flexion and abduction.

The Independent t-test was used to compare the scapula lateral slide, and as seen in Table 3, no significant difference was observed between the two groups $(\mathrm{P}<0.05)$. The Mann-Whitney test was used to compare the two groups as regards to scapula dyskinesis. The results of this test showed that there are no statistically significant differences between the two groups $(\mathrm{P}<0.05)$, although the obvious and subtle dyskinesis were located in the same category and were considered as disorders in the movement natural rhythm. According to Table 4, regarding the distribution of dyskinesia in the groups under study, by using the crosstabs test, dyskinesis was seen as more common in people with rounded shoulders as compared to those without rounded shoulders.

\section{Discussion}

In the present study, we used Kibler lateral scapular slide test (LSST) that assesses scapular kinematics in the static form. This test takes place in three positions. However, according to the results of previous studies and the present one, only one of these positions (first position) has high reproducibility [39]. Therefore, in this study, only the first position was examined for comparison. The results of this study showed that although the mean value of the distance between the seventh and eighth vertebrae to the inferior angle of scapula (the position of scapula in the Kibler test first position) in two right and left sides in the group with rounded shoulders was more than healthy persons, it is not statistically significant.

Previous studies have shownthat the posture of the rounded shoulder is due to the change in the scapula position. One of these changes, or in other words, one of the components related to RSP, is the protraction or abduction of the scapula [10,42]. However, the results of the present study did not show any significant difference between the two groupswith regards to the position of the scapula in the relaxing position, which was examined 
Table 4. Incidence of dyskinesis in both dominant and non-dominant sides in 2 groups of with and without rounded shoulder.

\begin{tabular}{|c|c|c|c|c|c|c|c|c|}
\hline Variable & Group & Present conditions & & & & & P-value & Mann-Whitey \\
\hline \multirow{7}{*}{$\begin{array}{l}\text { Scapular dyskinesis } \\
\text { in the right side } \\
\text { flexion }\end{array}$} & \multirow{4}{*}{ Healthy } & Normal & 11 & 11 & 47.8 & 47.8 & \multirow{7}{*}{0.65} & \multirow{7}{*}{223.5} \\
\hline & & Subtle & 9 & & 39.1 & & & \\
\hline & & & & 12 & & 52.1 & & \\
\hline & & Obvious & 3 & & 13.0 & & & \\
\hline & \multirow{3}{*}{$\begin{array}{l}\text { Rounded } \\
\text { shoulder }\end{array}$} & Normal & 9 & 9 & 42.9 & 42.9 & & \\
\hline & & Subtle & 8 & \multirow{2}{*}{12} & 38.1 & \multirow{2}{*}{57.1} & & \\
\hline & & Obvious & 4 & & 19.0 & & & \\
\hline \multirow{7}{*}{$\begin{array}{l}\text { Scapular dyskinesis } \\
\text { in the right side } \\
\text { abduction }\end{array}$} & \multirow{4}{*}{ Healthy } & Normal & 15 & 15 & 65.2 & 65.2 & \multirow{7}{*}{0.14} & \multirow{7}{*}{185.5} \\
\hline & & Subtle & 7 & & 30.4 & & & \\
\hline & & & & 8 & & 34.7 & & \\
\hline & & Obvious & 1 & & 3.4 & & & \\
\hline & \multirow{3}{*}{$\begin{array}{l}\text { Rounded } \\
\text { shoulder }\end{array}$} & Normal & 9 & 9 & 42.94 & 42.9 & & \\
\hline & & Subtle & 10 & \multirow[b]{2}{*}{12} & 47.6 & \multirow[b]{2}{*}{57.1} & & \\
\hline & & Obvious & 2 & & 9.5 & & & \\
\hline \multirow{8}{*}{$\begin{array}{l}\text { Scapular dyskine- } \\
\text { sis in the left side } \\
\text { flexion }\end{array}$} & \multirow{4}{*}{ Healthy } & Normal & 8 & 8 & 34.8 & 34.8 & \multirow{8}{*}{0.54} & \multirow{8}{*}{217.5} \\
\hline & & Subtle & 10 & & 43.5 & & & \\
\hline & & & & 15 & & 65.2 & & \\
\hline & & Obvious & 5 & & 21.7 & & & \\
\hline & \multirow{4}{*}{$\begin{array}{l}\text { Rounded } \\
\text { shoulder }\end{array}$} & Normal & 5 & 5 & 23.8 & 23.8 & & \\
\hline & & Subtle & 11 & \multirow{3}{*}{16} & 52.4 & \multirow{3}{*}{76.2} & & \\
\hline & & & & & & & & \\
\hline & & Ubvious & 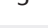 & & 23.0 & & & \\
\hline \multirow{8}{*}{$\begin{array}{l}\text { Scapular dyskine- } \\
\text { sis in the left side } \\
\text { abduction }\end{array}$} & \multirow{5}{*}{ Healthy } & Normal & 8 & 8 & 34.8 & 34.8 & \multirow{8}{*}{0.28} & \multirow{8}{*}{201.0} \\
\hline & & Subtle & 13 & & 56.5 & & & \\
\hline & & & & 15 & & 65.2 & & \\
\hline & & Obvious & 2 & & 8.7 & & & \\
\hline & & Normal & 5 & 5 & 23.8 & 23.8 & & \\
\hline & \multirow{3}{*}{$\begin{array}{l}\text { Rounded } \\
\text { shoulder }\end{array}$} & Subtle & 12 & \multirow{3}{*}{16} & 57.1 & \multirow{3}{*}{76.1} & & \\
\hline & & & & & & & & \\
\hline & & Obvious & 4 & & 19.0 & & & \\
\hline
\end{tabular}

PHYSICAL TREA TMENTS

by Kibler LSST. Nevertheless, it is noteworthy thatthe average distance measured in individuals with rounded shoulders was more than that in healthy group, which is somehow in line with these studies and partially confirms that the change in

the scapular position in relaxing or resting mode was due to the alteration in the shoulder posture. More importantly, the test to measure scapula lateral slide (which was used in this research) can only distinguish changes of more than 1 to $1.5 \mathrm{~cm}$ [39] and therefore, is not responsive to smaller changes; this may be a reason for the insignificant recorded results.
It is often said that the increase in hunched back or reclining posture leads to reduction [28] of upward rotation $[26,28]$, posterior tilt $[28,29]$, and external rotation of the scapula. The results of some studies on patients with rotator cuff disorders, especially those with the impingement syndrome, showed similar alterations in scapula kinematic patterns [43] and are similar to changes de scribed in the scapula position of persons with rounded shoulder. Likewise, in 1995, Greenfield et al., after examination of bodily postures of 30 patients with injuries caused by shoulder overuse (overuse injury), found that a number of them suffered from the impingement syndrome.However, when they compared them with 30 healthy individuals, they did not find any significant differences between the two groups with regard to the pro- 
traction level, shoulder rotation, back intermediate curvature, and scapular symmetry [11]. Also, in Ludewig's study on 52 laborers who had performed daily overhead activities (26 healthy laborers and 26 laborers with subacromial impingement syndrome), there were no significant differences between the laborers with subacromial impingement syndrome and the healthy individuals with regard to the scapula relaxing position [44]. The results of these studies are consistent with the result of the present study; however, it should be noted that the groups under study comprised of people suffering from the impingement syndrome.

Considering the three-dimensional movement of the scapula during the upper limb elevation, many researchers suggested the dynamic measurement methods as more appropriate for the scapula $[20,21]$. The method provided by Kibler for measuring scapula lateral slide in three static positions of the upper limb examines the scapula in the static position [5]. In contrast, there are methods that study the scapula's movement in the dynamic form. The method proposed by Mcclure in 2009 is one among them. In this method, scapular dyskinesis is examined in the dynamic position [22]. In the present study, the scapular lateral slide was examined in the static position. Therefore, the probable differences may not have been discernible by this method, which may lead to the conclusion that differences were not significant.

In 2006, Tighpen [45] compared and examined muscular activity, scapular kinematic, and shoulder joint coordination in individuals with and without rounded shoulder and forward head posture who did not suffer from pain in their shoulders. He used an electromagnetic tracking system and surface electromyography during shoulder flexion and overhead reaching task.People with rounded shoulder and forward head posture showed a significant increase in upward rotation, internal rotation, and scapula anterior taping when performing both movements. Thus, the electromagnetic tracking system is far more accurate than the method used in the present study and can record and show the minutest changes.

In 2015, Lopes [46] examined shoulder muscular activity and scapular kinematic in 38 patients suffering from shoulder impingement syndrome, 19 of them with and 19 without dyskinesis. He reported a decrease in scapula external rotation and an increase in the activity of superior trapezius muscle, accompanied with more loss of shoulder function in patients with impingement syndrome who had dyskinesis as compared with the group without dyskinesis. These differences may be compensatory strategies or causes. Some studies [44, 47] have reported an increase in internal rotation of scapula in patients with subacromial impingement syndrome while other studies [12, 48, 49] did not find any differences between internal or external rotation in these patients.

According to most studies, it seems that the change in normal posture and RSP may lead to a kind of scapular kinematic. In other words, it may affect scapulohumeral normal coordination and rhythm. However, in the present study and based on the scapular dyskinesis test, no significant difference was observed between the two study groups. It is noteworthy thatthe incidence of dyskinesis was more common in patients with RSP as compared with healthy individuals. This result is somehow consistent with the results of the studies mentioned above. Also, the scapular dyskinesis test places the scapular movement disorder only in 3 categories and therefore, is not a sensitive criterion to record minute changes [22]. This issue might be the reason no difference was seen between the two groups. Other reasons for our different results compared to that of the other studies include the difference between the assessment methods employed and also the difference between the groups under study. In most studies, the groups under study comprised of people with damage to their shoulders such as impingement syndrome and not those with RSP who were subjects of our study.

Usually, conducting any research depending on its conditions and features has some related limitations and difficulties. For more accurate examination of the scapula movement pattern, it would have been better if a motion analysis system was employed. Unfortunately, when this research was being conducted, access to such device was not possible.

The results of this study showed that in individuals with rounded shoulder, the position of scapula does not change. Furthermore, although the extent of subtle and obvious dyskinesis in persons with RSP was more than that in persons without a rounded shoulder, this difference was not statistically significant.

Considering the larger incidence of scapular dyskinesis in individuals with RSP, it is recommended that in preventive and rehabilitation programs for persons with RSP, muscle strengthening, which is useful in scapula stability and movement, should be considered.

\section{Acknowledgments}

This paper was extracted from the first author' MSc. thesis. 


\section{Conflict of Interests}

The authors declared no conflict of interests.

\section{References}

[1] Levangie PK, Norkin CC. Joint structure and function: a comprehensive analysis. Philadelphia: F. A. Davis; 2001.

[2] Magarey ME, Jones MA. Dynamic evaluation and early management of altered motor control around the shoulder complex. Manual Therapy. 2003; 8(4):195-206.

[3] Ekstrom RA, Soderberg GL, Donatelli RA. Normalization procedures using maximum voluntary isometric contractions for the serratus anterior and trapezius muscles during surface EMG analysis. Journal of Electromyography and Kinesiology. 2005; 15(4):418-28.

[4] Plafcan DM, Turczany PJ, Guenin BA, Kegerreis S, Worrell TW. An objective measurement technique for posterior scapular displacement. Journal of Orthopaedic \& Sports Physical Therapy. 1997; 25(5):336-41.

[5] Kibler WB. The role of the scapula in athletic shoulder function. American Journal of Sports Medicine. 1998; 26(2):32537.

[6] Najafi M, Behpoor N, Gaeeni S, Hosseintalaei Y. [Effect of selected stretch-strength exercises on primary school girls with forward shoulder deformity (Persian)]. Journal of Rehabilitation Medicine. 2013; 1(2):53-59.

[7] Griegel-Morris P, Larson K, Mueller-Klaus K, Oatis CA. Incidence of common postural abnormalities in the cervical, shoulder, and thoracic regions and their association with pain in two age groups of healthy subjects. Physical Therapy. 1992; 72(6):425-31.

[8] Kotteeswaran K, Rekha K, Anandh V. Effect of Stretching and Strengthening Shoulder Muscles in Protracted Shoulder in Healthy Individuals. International Journal of Computer Application; 2(2):111-18.

[9] Peterson DE, Blankenship KR, Robb JB, Walker MJ, Bryan JM, Stetts DM, et al. Investigation of the validity and reliability of four objective techniques for measuring forward shoulder posture. Journal of Orthopaedic \& Sports Physical Therapy. 1997; 25(1):34-42.

[10] Wong CK, Coleman D, Song J, Wright D. The effects of manual treatment on rounded-shoulder posture, and associated muscle strength. Journal of Bodywork and Movement Therapies. 2010; 14(4):326-33.

[11] Greenfield B, Catlin PA, Coats PW, Green E, McDonald JJ North C. Posture in patients with shoulder overuse injuries and healthy individuals. Journal of Orthopaedic \& Sports Physical Therapy. 1995; 21(5):287-95.

[12] Lukasiewicz AC, McClure P, Michener L, Pratt N, Sennett B. Comparison of 3-dimensional scapular position and orientation between subjects with and without shoulder impingement. Journal of Orthopaedic \& Sports Physical Therapy. 1999; 29(10):574-86.
[13] Sahrmann S. Diagnosis and treatment of movement impairment syndromes. New York: Elsevier Health Sciences; 2002.

[14] Wang CH, McClure P, Pratt NE, Nobilini R. Stretching and strengthening exercises: their effect on three-dimensional scapular kinematics. Archives of Physical Medicine and Rehabilitation. 1999; 80(8):923-29.

[15] Borstad JD, Ludewig PM. The effect of long versus short pectoralis minor resting length on scapular kinematics in healthy individuals. Journal of Orthopaedic \& Sports Physical Therapy. 2004; 35(4):227-38.

[16] Savadatti R, Gaude GS. Effect of forward shoulder posture on forced vital capacity-A Co-relational Study. Indian Journal of Physiotherapy and Occupational Therapy. 2011; 5(2):119-23.

[17] Kibler WB, Sciascia A, Wilkes T. Scapular dyskinesis and its relation to shoulder injury. Journal of the American Academy of Orthopaedic Surgeons. 2012; 20(6):364-72. doi: 10.5435/JAAOS-20-06-364

[18] Julius A, Lees R, Dilley A, Lynn B. Shoulder posture and median nerve sliding. BMC Musculoskeletal Disorders. 2004; 5(1):23. doi: 10.1186/1471-2474-5-23

[19] Smith J, Kotajarvi BR, Padgett DJ, Eischen JJ. Effect of scapular protraction and retraction on isometric shoulder elevation strength. Archives of Physical Medicine and Rehabilitation. 2002; 83(3):367-70. doi: 10.1053/apmr.2002.29666

[20] Karduna AR, McClure PW, Michener LA, Sennett B. Dynamic measurements of three-dimensional scapular kinematics: a validation study. Journal of Biomechanical Engineering. 2001; 123(2):184-90

[21] McClure PW, Michener LA, Sennett BJ, Karduna AR. Direct 3-dimensional measurement of scapular kinematics during dynamic movements in vivo. Journal of Shoulder and Elbow Surgery. 2001; 10(3):269-77.

[22] McClure P, Tate AR, Kareha S, Irwin D, Zlupko E. A clinical method for identifying scapular dyskinesis, part 1: reliability. Journal of Athletic Training. 2009; 44(2):165-73. doi: 10.4085/1062-6050-44.2.165

[23] Carter J, Banister E. Musculoskeletal problems in VDT work: a review. Ergonomics. 1994; 37(10):1623-648.

[24] Watanabe S, Eguchi A, Kobara K, Ishida H. Influence of trunk muscle co-contraction on spinal curvature during sitting for desk work. Electromyography and Clinical Neurophysiology. 2007; 47(6):273-78.

[25] Chansirinukor W, Wilson D, Grimmer K, Dansie B. Effects of backpacks on students: measurement of cervical and shoulder posture. Australian Journal of Physiotherapy. 2001; 47(2):110-16

[26] Finley MA, Lee RY. Effect of sitting posture on 3-dimensional scapular kinematics measured by skin-mounted electromagnetic tracking sensors. Archives of Physical Medicine and Rehabilitation. 2003; 84(4):563-68.

[27] Kalra N, Seitz AL, Boardman III ND, Michener LA. Effect of posture on acromiohumeral distance with arm elevation in subjects with and without rotator cuff disease using ultrasonography. Journal of Orthopaedic \& Sports Physical Therapy. 2010; 40(10):633-40. 
[28] Kebaetse M, McClure P, Pratt NA. Thoracic position effect on shoulder range of motion, strength, and three-dimensional scapular kinematics. Archives of Physical Medicine and Rehabilitation. 1999; 80(8):945-50.

[29] Lewis JS, Green A, Wright C. Subacromial impingement syndrome: the role of posture and muscle imbalance. Journal of Shoulder and Elbow Surgery. 2005; 14(4):385-92.

[30] Silva RT, Hartmann LG, de Souza Laurino CF, Biló JR. Clinical and ultrasonographic correlation between scapular dyskinesia and subacromial space measurement among junior elite tennis players. British Journal of Sports Medicine. 2010; 44(6):407-10.

[31] Kendall FP, McCreary EK, Provance PG, Rodgers MM, Romani W. Muscles, testing and function: with posture and pain. Washington, D.C.: Lippincott Williams \& Wilkins; 1993.

[32] Lewis JS, Valentine RE. The pectoralis minor length test: a study of the intra-rater reliability and diagnostic accuracy in subjects with and without shoulder symptoms. BMC Musculoskeletal Disorders. 2007; 8(1):64. doi: 10.1186/14712474-8-64

[33] Han JT, Lee JH, Yoon CH. The mechanical effect of kinesiology tape on rounded shoulder posture in seated male workers: a single-blinded randomized controlled pilot study. Physiotherapy Theory and Practice. 2015; 31(2):12025 .

[34] Nejati P, Lotfian S, Moezy A, Nejati M. The study of correlation between forward head posture and neck pain in Iranian office workers. International Journal of Occupational Medicine and Environmental Health. 2014; 28(2):295-303.

[35] Thigpen CA, Padua DA, Michener LA, Guskiewicz K, Giuliani C, Keener JD, et al. Head and shoulder posture affect scapular mechanics and muscle activity in overhead tasks. Journal of Electromyography and kinesiology. 2010; 20(4):701-09.

[36] Cole AK, McGrath ML, Harrington SE, Padua DA, Rucinski TJ, Prentice WE. Scapular bracing and alteration of posture and muscle activity in overhead athletes with poor posture. Journal of Athletic Training. 2013; 48(1):12.

[37] Gupta BD, Aggarwal S, Gupta B, Gupta M, Gupta N. Effect of deep cervical flexor training vs. conventional isometric training on forward head posture, pain, neck disability index in dentists suffering from chronic neck pain. Journal of Clinical and Diagnostic Research. 2013; 7(10):2261-264.

[38] Hundekari J, Chilwant K, Vedpathak S, Wadde S. Does alteration in backpack load affect posture of school children? Group. Journal of Dental and Medical Sciences. 2013; 7(4):71-75.

[39] Crotty NN, Smith J. Alterations in scapular position with fatigue: a study in swimmers. Clinical Journal of Sport Medicine. 2000; 10(4):251-58.

[40] Tate AR, McClure P, Kareha S, Irwin D, Barbe MF. A clinical method for identifying scapular dyskinesis, part 2: validity. Journal of Athletic Training. 2009; 44(2):165-73.

[41] Rafał S, Janusz M, Wiesław O, Robert S. Test-retest reliability of measurements of the center of pressure displacement in quiet standing and during maximal voluntary body lean- ing among healthy elderly men. Journal of Human Kinetics. 2011; 28:15-23. doi: 10.2478/v10078-011-0018-9

[42] DiVeta J, Walker ML, Skibinski B. Relationship between performance of selected scapular muscles and scapular abduction in standing subjects. Physical Therapy. 1990; 70(8):470-76.

[43] Ludewig PM, Reynolds JF. The association of scapular kinematics and glenohumeral joint pathologies. Journal of Orthopaedic \& Sports Physical Therapy. 2009; 39(2):90-104.

[44] Ludewig PM, Cook TM. Alterations in shoulder kinematics and associated muscle activity in people with symptoms of shoulder impingement. Physical Therapy. 2000; 80(3):27691.

[45] Thigpen CA. Effects of Forward Head and Rounded Shoulder Posture on Scapular Kinematics, Muscle Activity, and Shoulder Coordination [PhD dissertation]. Chapel Hill: University of North Carolina at Chapel Hill; 2006.

[46] Lopes AD, Timmons MK, Grover M, Ciconelli RM, Michener LA. Visual scapular dyskinesis: kinematics and muscle activity alterations in patients with subacromial impingement syndrome. Archives of Physical Medicine and Rehabilitation. 2015; 96(2):298-306.

[47] Hébert LJ, Moffet H, McFadyen BJ, Dionne CE. Scapular behavior in shoulder impingement syndrome. Archives of Physical Medicine and Rehabilitation. 2002; 83(1):60-69.

[48] Endo K, Ikata T, Katoh S, Takeda Y. Radiographic assessment of scapular rotational tilt in chronic shoulder impingement syndrome. Journal of Orthopaedic Science. 2001; 6(1):3-10.

[49] McClure PW, Michener LA, Karduna AR. Shoulder function and 3-dimensional scapular kinematics in people with and without shoulder impingement syndrome. Physical Therapy. 2006; 86(8):1075-090. 
